\title{
PEMANFAATAN SMS GATEWAY DENGAN GAMMU DAN WEBCAM BERBASIS VISUAL BASIC 6.0 PADA SISTEM KEAMANAN RUMAH
}

\author{
Muhammad Ishaq Islahuddin, Arkhan Subari \\ Program Studi Diploma III Teknik Elektro \\ Fakultas Teknik Universitas Diponegoro
}

\begin{abstract}
Muhammad Ishaq Islahuddin, Arkhan Subari, in this paper explain that in a home security system is very important information dissemination system. One of them by the use of SMS Gateway. By using Gammu and MySQL as a database and use a webcam as a tool for monitoring room in the house. The way this system works is a home security system using a PIR sensor detecting human movement. After that, if the data from the sensors in the microcontroller. Microcontroller then sends the data to a computer through a serial port. On the computer there is a VB 6.0 application. when the PIR sensor detects the presence of a human, the computer will be otomstis capture and send SMS alerts to a database of numbers that have been stored.
\end{abstract}

Keywords : Webcam, SMS Gateway, Gammu, MySQL, Visual Basic 6.0 .

\section{PENDAHULUAN \\ Latar Belakang}

Pada era modern ini, kemajuan teknologi sangatlah pesat terutama di bidang penyebaran sistem informasi. Salah satu sistem penyebaran informasi yang sering digunakan pada saat ini misalnya berupa SMS(Short Message Service). SMS sering digunakan untuk mengirim pesan antara Handphone satu dengan yang lain. Pemanfaatan SMS dalam suatu sistem aplikasi untuk penyebaran informasi juga banyak digunakan. Misalnya untuk mengirim informasi tentang letak posisi suatu barang dalam suatu aplikasi. Sebenarnya pemanfaatan SMS dalam penyebaran suatu informasi sangatlah banyak dan mudah di kembangkan.

Dalam suatu sistem keamanan rumah sistem penyebaran informasi sangatlah penting. Sistem ini bisa memanfaatan SMS sebagai penyebaran informasi. Jadi dengan menggunakan SMS kita bisa mengetahui keadaan rumah dimanapun kita berada dan kapan saja. Sistem SMS Gateway ini menggunakan gammu dan MySQL sebagai database. Dengan menggunakan webcam sebagai alat untuk monitoring ruangan dalam rumah.

\section{Tujuan}

Tujuan yang ingin dicapai adalah memanfaatkan SMS Gateway dengan gammu dan webcam sebagai system informasi pada suatu keamanan rumah yang dirancang dengan menggunakan pemrograman visual basic 6.0.

\section{Batasan Masalah}

Dalam penelitian ini ada beberapa batasan masalah, yaitu sistem SMS Gateway dengan GAMMU, Penggunaan Modem Wavecom M1306B USB sebagai alat untuk mengirimkan SMS, Penggunaan software visual basic 6.0 yang sebagai perancangan perangkat lunak untuk mengakses webcam dan pengiriman SMS, MySQL sebagai penyimpanan database, Komunikasi serial sebagai antarmuka antara sistem minimum mikrokontroller dengan computer menggunakan RS 232, Penggunaan webcam Sturdy 511 sebagai alat untuk menangkap gambar pada ruangan.

\section{LANDASAN TEORI}

SMS (Short Message Service)

Short Message Service (SMS) (Hendarto, Chun Chun. 2009) adalah salah satu tipe Instant Messaging (IM) yang memungkinkan user untuk bertukar pesan singkat kapanpun walaupun user sedang melakukan sambungan data/suara. SMS dihantarkan pada channel signal GSM (Global System for Mobile Communication) spesifikasi teknis ETSI. SMS diaktifkan oleh ETSI dan dijalankan di scope 3GPP. SMS juga digunakan pada teknnologi GPRS dan CDMA. SMS menjamin pengiriman pesan oleh jaringan, jika terjadi kegagalan pesan akan disimpan dahulu di jaringan, pengiriman paket SMS bersifat out of band dan menggunakan bandwidth rendah.

\section{Mekanisme Kerja SMS}

Mekanisme kerja Pengiriman SMS dapat dibagi menjadi 3 macam (Informatika, 2012), yaitu:

- Pengiriman SMS Intra-Operator (satu operator)

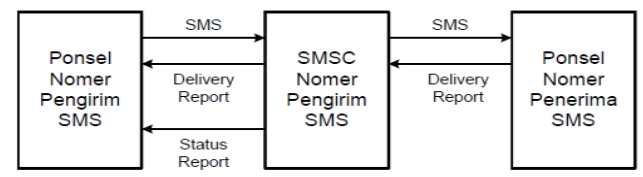

Mekanisme intra-operator SMS

Gambar 1. Mekanisme intra-operator SMS

SMS yang dikirimkan oleh nomor pengiriman akan dimasukkan terlebih dahulu ke dalam SMSC operator nomor pengirim, kemudian SMSC tersebut akan mengirimkan ke nomor tujuan secara langsung. Nomor penerima akan mengirimkan delivery report yang menyatakan 
bahwa SMS telah diterima kepada SMSC, SMSC kemudian meneruskan report tersebut kepada nomor pengirim SMS, disertai status report dari proses pengiriman SMS tersebut

- Pengiriman SMS Interoperator (operator yang berbeda)

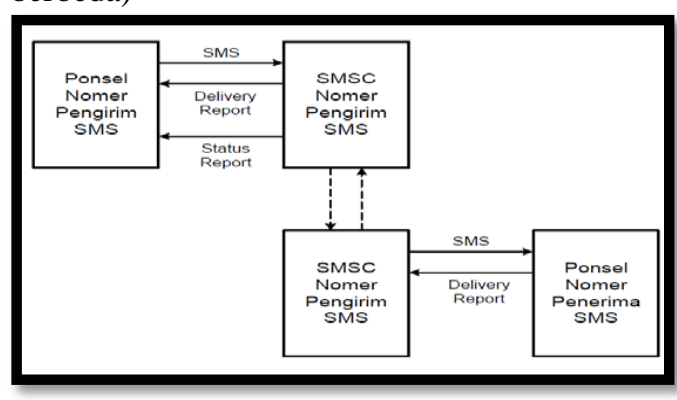

Gambar 2. Mekanisme inter-operator

Selain masuk ke SMSC operator pengirim, SMS yang dikirimkan akan diteruskan oleh SMSC operator pengirim ke SMSC operator penerima SMS, kemudian baru diteruskan ke nomor tujuan, Delivery report yang dihasilkan pun harus melewati mekanisme yang sama sebelum di terima oleh nomor pengirim.

- Pengiriman SMS dari operator suatu Negara ke Negara lain (SMS Internasional)

Mekanisme yang terjadi tidak jauh berbeda dengan mekanisme pada inter-operator SMS. Perbedaannya hanya pada SMSC nomor penerima, yang tentu sajaadalah SMSC operator luar negeri, dan penambahan kode negara pada nomor tujuan.

\section{Arsitektir SMS}

SMS dimaksudkan untuk menjadi alat pertukaran informasi antara dua mobile subscriber. Elemen-elemen utama pada arsitektur SMS terdiri dari Short Message Entity (SME), SMS Centre (SMSC) dan Email Gateway yang terkoneksi dengan elemen-elemen pada GSM sebagai channel penghantar (Prihatin, Ekawati. 2006). Gambar 3 yang menunjukkan arsitektur SMS pada jaringan GSM

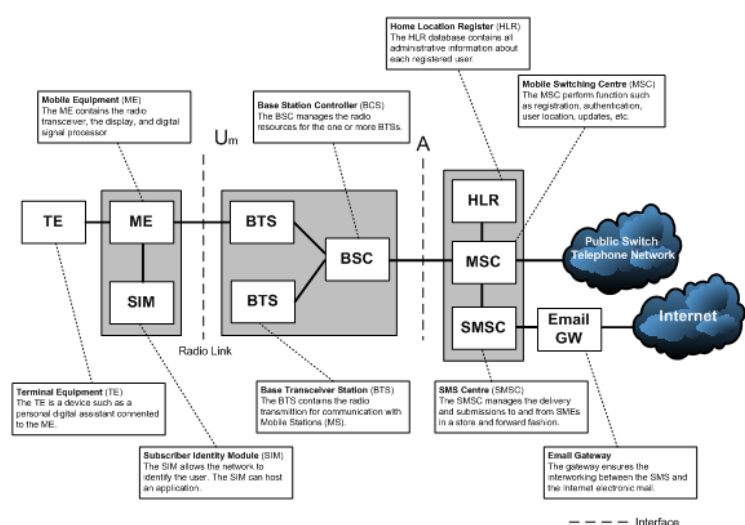

Gambar 3. Arsitektur SMS

\section{SMS Gateway}

Pada prinsipnya, SMS Gateway adalah sebuah perangkat lunak yang diaplikasikan ke dalam komputer dan dengan memanfaatkan teknologi seluler yang diintegrasikan guna mendistribusikan pesan-pesan yang di-generate lewat sistem informasi melalui media SMS yang di-handle oleh jaringan seluler.

\section{GAMMU}

GAMMU (GNU All Mobile Management Utilities) adalah adalah nama sebuah project yang ditujukan untuk membangun aplikasi, script dan drivers yang dapat digunakan untuk semua fungsi yang memungkinkan pada telepon seluler atau alat sejenisnya. Sekarang GAMMU telah menyediakan codebase yang stabil dan mapan untuk berbagai macam model telepon yang tersedia di pasaran dibandingkan dengan project sejenis .

GAMMU merupakan project yang berlisensi GNU GPL 2 sehinggamenjamin kebebasan menggunakan tool ini tanpa perlu takut dengan masalah legalitas dan biaya yang mahal yang harus dikeluarkan. GAMMU mendukung berbagai macam model telepon seluler dengan berbagai jenis koneksi dan type. (www.gammu.org).

GAMMU merupakan software SMS gateway yang cukup bagus dan terkenal. Selain mudah penggunaannya, perangkat modem GSM yang support cukup banyak mulai dari nokia, siemen, Sonny ericsson, dll. Informasi mengenai ponsel apa saja yang didukung oleh GAMMU, dapat dicari melalui situs http://wammu.eu/phones/. GAMMU bahkan sudah menyediakan service online untuk proses update data SMS ke database.

Database yang di support GAMMU adalah MySQL, ada beberapa pihak yang menginginkan program SMS gateway nya menggunakan database yang lain seperti SQLserver, Oracle dan lain-lain. Dengan menggunkan sedikit program tambahan (delphi atau vb) kita bisa membuat service atau program yang memanfaatkan GAMMU dan SQLserver sebagai databasenya.

\section{File Konfigurasi GAMMU}

File konfigurasi dalam GAMMU ini ada 2 yaitu Gammurc dan SMSdrc (Aplikasi PHP, 2012). Kedua file ini memiliki fungsi dan kegunaan masing-masing. Biasanya file Gammurc digunakan untuk melakukan pengecekan koneksi antara Modem dengan GAMMU, apakah sudah terkoneksi atau tidak. Sedangkan SMSdrc biasanya digunakan untuk mengatur proses pengiriman dan penerimaan SMS.

\section{- Gammurc}

File gammurc digunakan untuk konfigurasi port yang digunakan media koneksi untuk terhubung ke komputer. Selain itu, file 
gammurc juga digunakan untuk mendefinisikan tipe koneksi yang digunakan oleh media koneksi.

\section{- $\quad$ SMSdrc}

File SMSdrc digunakan untuk konfigurasi database yang akan digunakan oleh aplikasi GAMMU.

\section{Webcam}

Webcam (singkatan dari webcamera) (Adie Flink, 2011) adalah sebutan bagi kamera real-time (bermakna keadaan pada saat ini juga) yang gambarnya bisa diakses atau dilihat melalui World Wide Web, program instant messaging atau aplikasi video call.

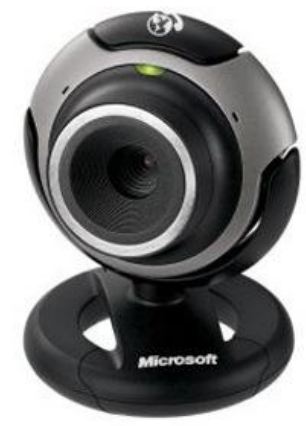

Gambar 4. webcam

Sebuah webcamera yang sederhana terdiri dari sebuah lensa standar, dipasang di sebuah papan sirkuit untuk menangkap sinyal gambar; casing (cover), termasuk casing depan dan casing samping untuk menutupi lensa standar dan memilikisebuah lubang lensa di casing depan yang berguna untuk memasukkan gambar; kabel support, yang dibuat dari bahan yang fleksibel, salah satu ujungnya dihubungkan dengan papan sirkuit dan ujung satu lagi memiliki connector, kabel ini dikontrol untuk menyesuaikan ketinggian, arah dan sudut pandang webcamera.

Sebuah webcamera biasanya dilengkapi dengan software, software ini mengambil gambargambar dari kamera digital secara terus menerus ataupun dalam interval waktu tertentu dan menyiarkannya melalui koneksi internet.

Webcamera memiliki fitur-fitur dan setting yang bermacam-macam, diantaranya adalah:

\section{- Motionsensing}

Webcamera akan mengambil gambar ketika kamera mendeteksi gerakan.

- Image archiving

Pengguna dapat membuat sebuah archive yang menyimpan semua gambar dari webcamera atau hanya gambar-gambar tertentu saat interval pre-set.

- Video messaging

Beberapa program messaging mendukung fitur ini.

- Advancedconnections
Menyambungkan perangkat home theater ke webcamera dengan kabel maupun nirkabel.

- Automotion

Kamera Robotik yang memungkinkan pengambilan gambar secara pan atau tilt dan setting program pengambilan frame berdasarkan posisi kamera.

- Streamingmedia

Aplikasi profesional, setup webcamera dapat menggunakan kompresi MPEG4untuk mendapatkan streaming audio dan video yang sesungguhnya.

- Customcoding

Mengimport kode komputer pengguna untuk memberitahu webcameraapa yang harus dilakukan (misalnya automatically refresh).

- AutoCam

Memungkinkan pengguna membuat web page untuk webcameranya secara gratis di server perusahaan pembuat webcamera.

MySQL

MySQL adalah sebuah implementasi dari sistem manajemen basisdata relasional yang didistribusikan secara gratis dibawah lisensi GPL (General Public License). Setiap pengguna dapat secara bebas menggunakan MySQL, namun dengan batasan perangkat lunak tersebut tidak boleh dijadikan produk turunan yang bersifat komersial. MySQL sebenarnya merupakan turunan salah satu konsep utama dalam basisdata yang telah ada sebelumnya; SQL (Structured Query Language). SQL adalah sebuah konsep pengoperasian basisdata, terutama untuk pemilihan atau seleksi dan pemasukan data, yang memungkinkan pengoperasian data dikerjakan dengan mudah secara otomatis.

\section{Pemrograman Visual Basic 6.0}

Microsoft Visual Basic 6.0 merupakan bahasa pemrograman yang cukup popular dan mudah untuk dipelajari. Kita dapat membuat program dengan aplikasi GUI (Graphical User Interface), atau program yang memungkinkan pengguna komputer dapat berkomunikasi menggunakan media grafik atau gambar dengan komputer tersebut.

Microsoft Visual Basic 6.0 menyediakan fasilitas yang memungkinkan menyusun sebuah program dengan memasang objek-objek grafis dalam sebuah form.

Visual Basic 6.0 berawal dari bahasa pemrograman BASIC (Beginners All-purpose Symbolic Instruction Code). Karena bahasa BASIC cukup nudah dipelajari dan populer, maka hampir setiap programmer menggunakan bahasa ini.

Pada tahun 1980-an, sistem operasi dos cukup popular di kalangan pengguna PC karena di dalamnya disertakan bahasa BASIC yang dikenal dengan QBASIC (QiuckBasic). Sistem tersebut 
sekarang sudah jarang digunakan. Di era Windows, Microsoft menciptakan Visual Basic yang terus mengalami penyempurnaan hingga Visual Basic 6.0. (Hasballah, Fajrillah. 2009)

\section{Komunikasi Data}

Mikroprosesor dalam komputer bekerja atas dasar prinsip data paralel, mula-mula banyak dipakai mikroprosesor dengan data paralel 8-bit dan kini sudah dipakai data paralel 32-bit, komunikasi data terdiri dari 2 jenis yaitu komunikasi data seri dan parallel. Komunikasi data seri yaitu transmisi serial, bit dikirim secara berurutan pada channel yang sama (kawat) yang mengurangi biaya untuk kawat tetapi juga memperlambat kecepatan transmisi. Sedangkan komunikasi data parallel yaitu Transmisi paralel, semua bit dari karakter yang diwakili oleh suatu kode, ditransmisikan secara serentak satu karakter setiap saat. Data dikirimkan terus menerus melalui jalur-jalur yang disediakan tersebut hingga semua data dapat terkirimkan.

\begin{tabular}{|c|c}
\hline $\mathrm{P}$ & 1 \\
$\mathrm{E}$ & 1 \\
$\mathrm{~N}$ & 0 \\
$\mathrm{G}$ & 1 \\
$\mathrm{I}$ & 1 \\
$\mathrm{R}$ & 0 \\
$\mathrm{I}$ & 0 \\
$\mathrm{M}$ & 1 \\
&
\end{tabular}
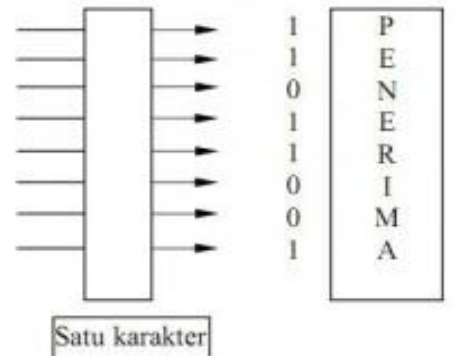

Gambar 5. Komunikasi Data Paralel

Model transmisi paralel biasanya digunakan untuk melakukan komunikasi jarak pendek. Contohnya, transmisi ke printer atau untuk komunikasi data dua buah komputer.

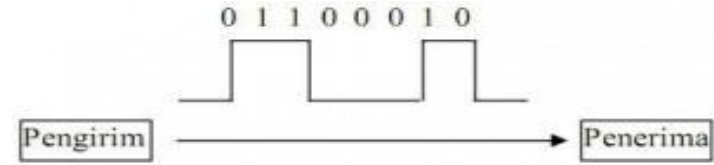

Gambar 6. Komunikasi Data Seri

Dalam hal komunikasi data yang dipakai adalah teknik pengiriman data secara seri. Alasan utama pemakaian teknik pengiriman seri karena saluran komunikasi data paralel yang panjang harganya sangat mahal dan tidak praktis. Ini disebabkan komunikasi secara paralel menggunakan jalur data lebih banyak daripada serial serta jangkauannya yang terbatas.Dengan demikian, meskipun kecepatan transmisi data dengan teknik komunikasi data secara paralel lebih cepat, teknik komunikasi data seri tetap dipilih untuk transmisi data jarak jauh.

Pada komunikasi serial biasanya digunakan DB 9 dengan konfigurasi pin ditunjukkan pada gambar 7 .

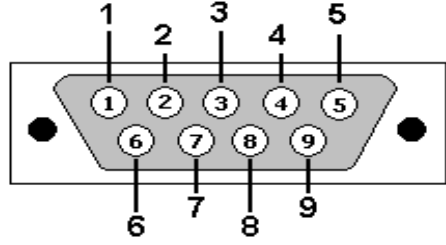

Gambar 7. Pin serial DB9

Table 1 adalah tabel yang menunjukkan pin konfigurasi dari DB9.

Tabel 1. Konfigurasi Pin DB9

\begin{tabular}{ccc}
\hline No. Pin & Nama Pin & Keterangan \\
\hline Pin 1 & CD & Carrier Detect \\
Pin 2 & RD & Receive Data \\
Pin 3 & TD & Transmit Data \\
Pin 4 & DTR & Data Transmit \\
& & Data \\
Pin 5 & SG & Signal Ground \\
Pin 6 & DSR & Data Set Ready \\
Pin 7 & RTS & Request To Sent \\
Pin 8 & CTS & Clear To sent \\
Pin 9 & R1 & Ring Indicator \\
\hline
\end{tabular}

\section{Modem}

Modem adalah singkatan dari modulator dan demodulator. Modulator berfungsi untuk melakukan proses menumpangkan data pada sinyal informasi ke sinyal pembawa agar dapat dikirim ke pengguna melalui media tertentu, proses ini biasa disebut dengan proses modulasi. pada proses ini data dari komputer yang berbentuk sinyal digital akan diubah menjadi sinyal analog. Sedangkan Demodulator berfungsi sebagai proses mendapatkan kembali data yang dikirim oleh pengirim. Pada proses ini data akan dipisahkan dari frekuensi tinggi dan data yang berupa sinyal analog akan diubah kembali menjadi sinyal digital agar bisa dibaca oleh komputer. Jadi kesimpulannya fungsi modem adalah sebuah perangkat keras yang berfungsi untuk komunikasi dua arah yang merubah sinyal digital menjadi sinyal analog atau sebaliknya untuk mengirimkan pesan/data ke alamat yang dituju. Bisa juga diartikan sebagai perantara untuk menghubungkan computer kita ke jaringan internet.

\section{PERANCANGAN SISTEM}

Sebuah sistem monitoring keamanan yang memanfaatkan SMS Gateway dengan GAMMU sebagai sistem penyaluran informasi dan webcam sebagai monitoring sistem. Sistem ini akan bekerja jika mikrokontroler memberikan sinyal atau trigger yang akan masuk lewat port serial. Mikrokontroler akan memberikan trigger apabila sensor PIR akan menangkap suatu gerakan manusia yang ada dalam ruangan. Ketika mikrokontroler memberikan trigger maka yang terjadi adalah sistem akan mengaktifkan fitur webcam yang ada pada aplikasi Visual Basic yang telah dibuat dan secara otomatis akan 
mengambil foto berdasarkan gerakan manusia yang tertangkap sensor PIR dan akan tersimpan dalam database. Sistem ini juga akan mengaktifkan fitur SMS yang ada pada visual basic yang tela dibuat dan secara otomatis akan mengirimkan SMS peringatan kepada nomor-nomor yang tersimpan pada database. Gambar 8 adalah adalah blog diagram dari sistem.

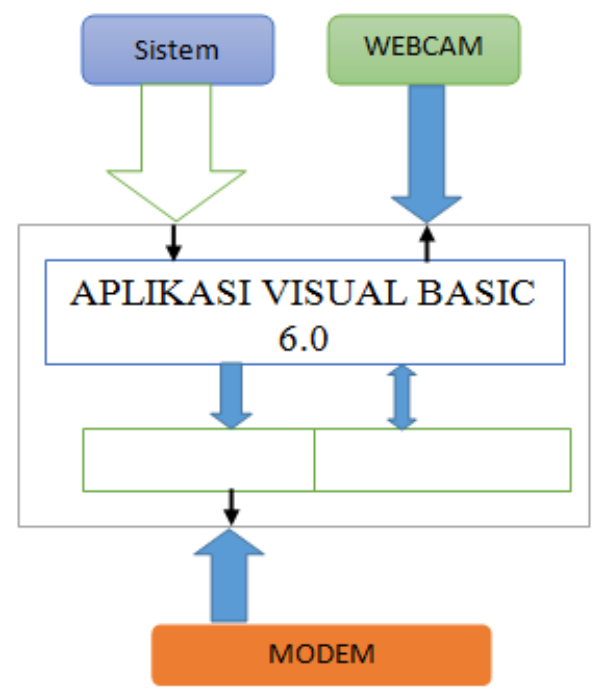

Gambar Blog Diagram

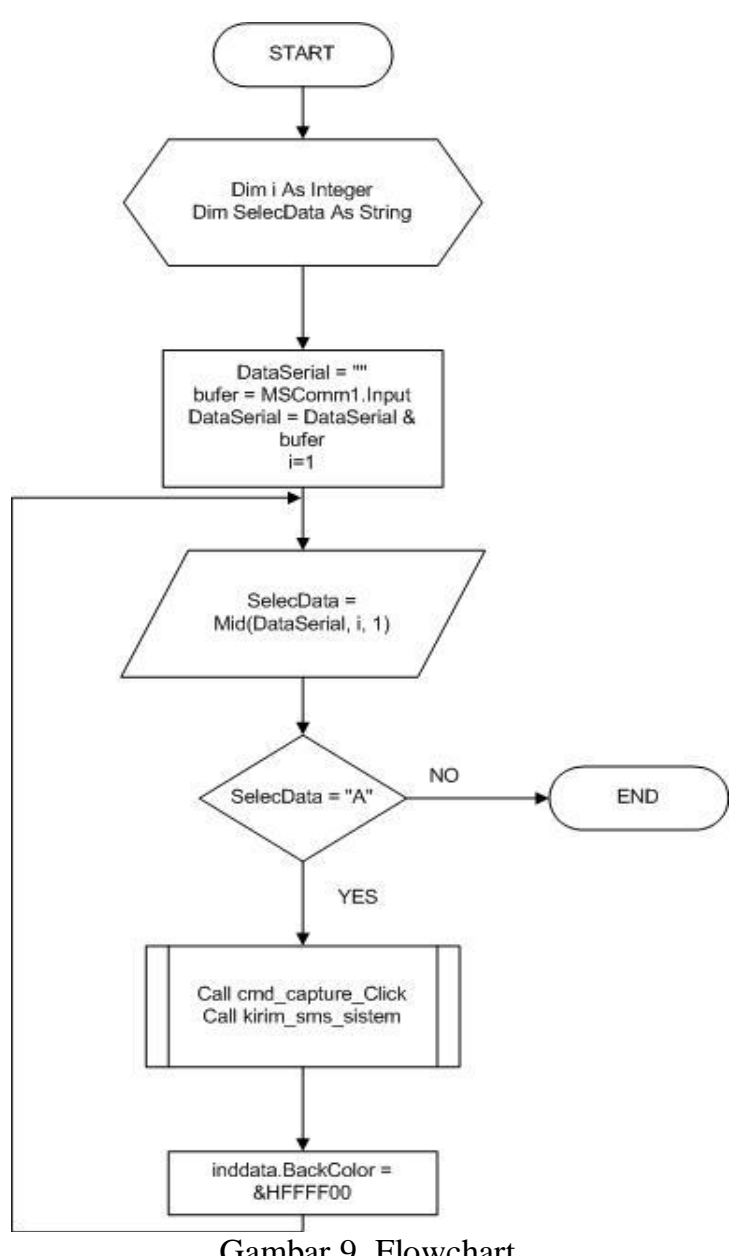

\section{IMPLEMENTASI SISTEM}

Pada dasarnya dalam mengimplementasikan pembuatan sistem ini dibagi menjadi 2 bagian yaitu :

- Pemasangan perangkat keras

Tahap pertama ini meliputi semua proses pemasangan perangkat keras untuk merealisasikan rancangan yang telah dibuat menjadi sistem yang siap untuk dioperasikan.

- Pembuatan software

Tahap kedua ini yaitu mencakup semua hal yang berkaitan dengan perangkat lunak bagi sistem.

Masing-masing bagian mempunyai tujuan yang sama yaitu agar kedua bagian yang merupakan satu kesatuan sistem yang akan dibuat dapat saling melengkapi satu sama lain sehingga tercipta suatu sistem yang baik. Langkah awal pembuatan tugas akhir ini adalah perencanaan dan konsep yang jelas tentang aplikasi yang akan dibuat. Agar kendalakendala yang tidak diinginkan pada proses pembuatan dapat diperhitungkan.

Dalam proses pembuatan aplikasi ini pembuatan software lebih ditekankan karena pokok bahasan pada aplikasi ini adalah software pemrograman visual basic 6.0. Sedangkan pemasangan hardware merupakan penunjang dari software aplikasi visual basic 6.0.

\section{Pemasangan Perangkat Keras}

Pemasangan perangkat keras ini bertujuan untuk menunjang software aplikasi monitoring.

Tabel 2. Perangkat Keras

\begin{tabular}{lcl}
\multicolumn{1}{c}{ Alat } & Jumlah & \multicolumn{1}{c}{ Fungsi } \\
\hline USB to Serial & 1 buah & digunakan untuk \\
DKU-5 & & $\begin{array}{l}\text { komunikasi RS 232 } \\
\text { pada PC ke }\end{array}$ \\
Seriner/N & & $\begin{array}{l}\text { mikrokontroller. } \\
\text { Wto48000317 }\end{array}$ \\
$\begin{array}{l}\text { Modem } \\
\text { Wavecom }\end{array}$ & 1 buah & $\begin{array}{l}\text { Digunakan untuk } \\
\text { servis GAMMU }\end{array}$ \\
M1306B & & \\
Webcam Sturdy & 1 buah & $\begin{array}{l}\text { Digunakan untuk } \\
\text { memonitor ruangan }\end{array}$ \\
\hline
\end{tabular}

\section{Instalasi GAMMU}

Langkah pertama pada instalasi GAMMU adalah copy file GAMMU ke dalam directory $\mathrm{C}$. setelah itu edit file gammurc seperti di bawah ini :

[gammu]

port $=$ com3: 'port com yang digunakan

connection = at115200"kode koneksi modem

selain merubah settingan gammurc, dalam instalasi GAMMU juga harus mensetting file smsdrc untuk berkomunikasi dengan database. Setting smsdrc adalah sebagai berikut:

port $=$ diisi nomor port sesuai yang ada di file GAMMURC

connection = diisi jenis connection sesuai yang ada di GAMMURC 
service = mysql (diisi dengan 'mysql' karena kita akan menggunakan mysql sebagai storage data SMSnya)

user $=$ diisi user database koneksi ke mysql password = diisi password koneksi ke mysql $p c=$ diisi nama host mysql (biasanya localhost)

database $=$ SMS (atau sesuai nama database yang tadi kita buat)

Untuk membuat GAMMUservice di Windows, ketikkan perintah "gammu-smsd -c smsdrc - $i$ " di DOS PROMPT setelah masuk ke folder 'C:Igammu'.

Bila ada konfirmasi bahwa proses pembuatan service sukses, maka akan terlihat service GAMMU muncul pada daftar service yang berjalan di Windows. Service ini bisa dilihat melalui 'CONTROL PANEL > Administrative Tools > Services'. Untuk menjalankan service GAMMU ini tinggal klik START pada service GAMMU tersebut.

\section{Pembuatan Database Sistem}

Database yang di rancang diberi namagatesms. Databaseterdiri dari 3 buah tabel buatan sendiri yaitu, tabel tbgambar, tbpenerima, tbsms. Kegunaan tabel - tabel tersebut adalah sebagai berikut.

\section{- tbgambar}

Tabel gambar berfungsi untuk menyimpan data hasil capture. Ketika mikrokontroler mengirim data ke computer maka yang terjadi adalah sistem akan meng-capture ruangan dan akan mengirimkan sms peringatan ke nomor penerima. Gambar yang ter-capture ini nantinya akan tersimpan pada tbgambar.

- tbpenerima

Tabel penerima digunakan untuk menyimpan database nomor penerima SMS. Jadi setiap SMS sistem akan terkirim pada nomor yang telah disimpan pada tabel tbpenerima.

- tbsms

Digunakan untuk menyimpan riwayat pengiriman SMS. Ketika ada mikrokontroler mengirim data ke computer lewat port serial (ada pergerakan terdeteksi) maka secara otomatis akan mengcapture gambar dan mengirim pesan. Tbsms berfungsi untuk menyimpan riwayat pengiriman pesan. Secara tidak labgsung tabel ini juga berfungsi menyimoan riwayat ketika ada suatu pergerakan yang terdeteksi.

\section{Pembuatan Aplikasi VB 6.0}

Halaman Utama (kfrm_Utama)

Halaman Utama berfungsi untuk menampilkan halaman awal pada aplikasi yang dibuat. Halaman utama dibuat dengan menggunakan frame. Pada halaman utama terdapat jendela webcam, jendela capture, tombol Start, tombol next/preview, capture, setting komunikasi, dan label waktu.

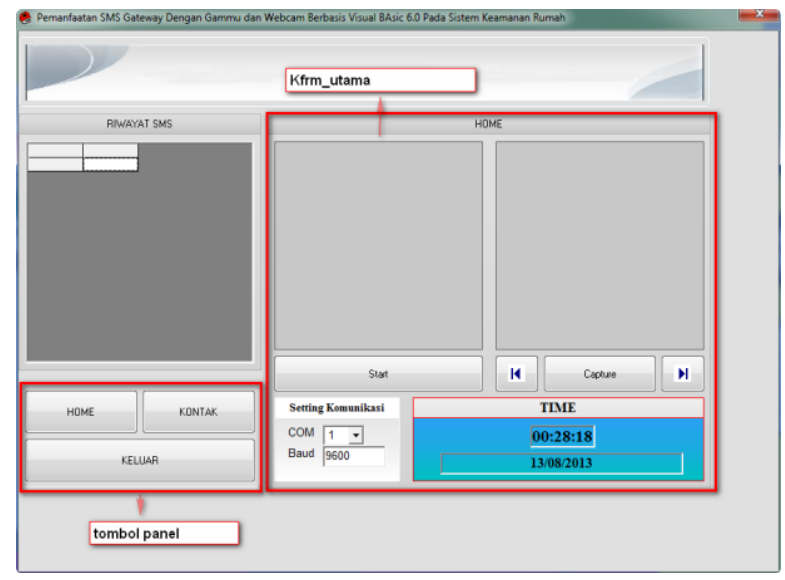

Gambar 10. Tampilan form utama

Halaman utama ini muncul ketika aplikasi mulai dijalankan. Tombol Home berfungsi untuk menampilkan halaman utama ketika berada pada halaman kontak.

\section{Halaman Kontak}

Halaman kontak berfungsi untuk menambah database penerima SMS.

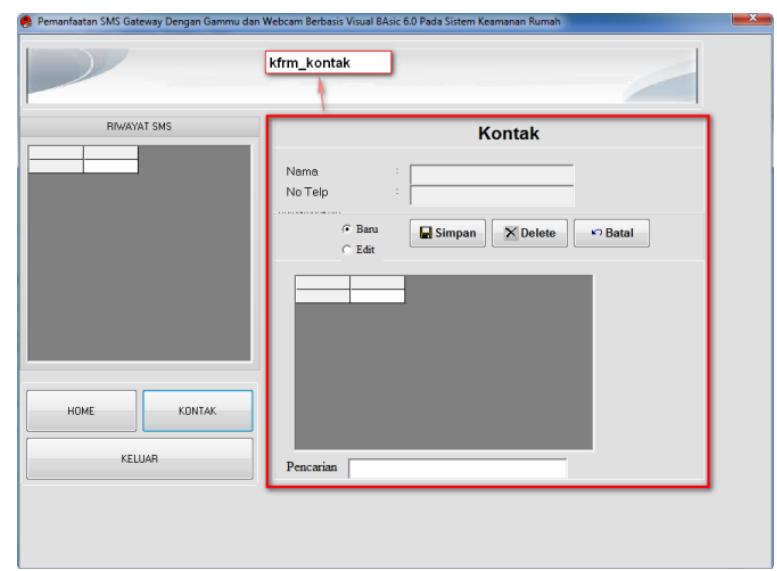

Gambar 11. Tampilan halaman kontal

\section{HASIL}

Pengujian ini dilakukan dengan mengoperasikan keseluruhan sistem meliputi hardware dan software yang digunakan dalam perancangan sistem keamanan rumah menggunakan sensor PIR berbasis mikrokontroller ATMega 8535.

\section{Pengujian dalam memulai dan mengakhiri sistem}

Dalam pengujian ini sistem akan di aktifkan dengan cara menekan tombol Start (cmdstart). Untuk memulai sistem mekanismenya adalah dengan cara menekan tombol start sekali. Setelah itu maka sistem akan mengaktifkan fitur kamera dan mengkoneksikan komputer dengan sistem keamanan rumah melalui port serial. Gambar 12 adalah gambar ketika sistem diaktifkan. 


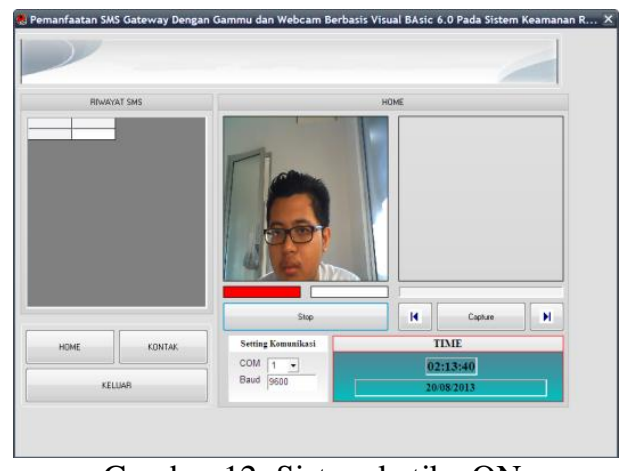

Gambar 12. Sistem ketika ON

Sedangkan untuk mematikan sistem mekanismenya adalah dengan cara menekan tombol start sekali lagi. Setelah itu sistem akan seperti semua. Fitur kamera akan mati dan koneksi antara PC dengan sistem keamanan akan terputus. Gambar 13. adalah gambar sistem ketika sudah mati.

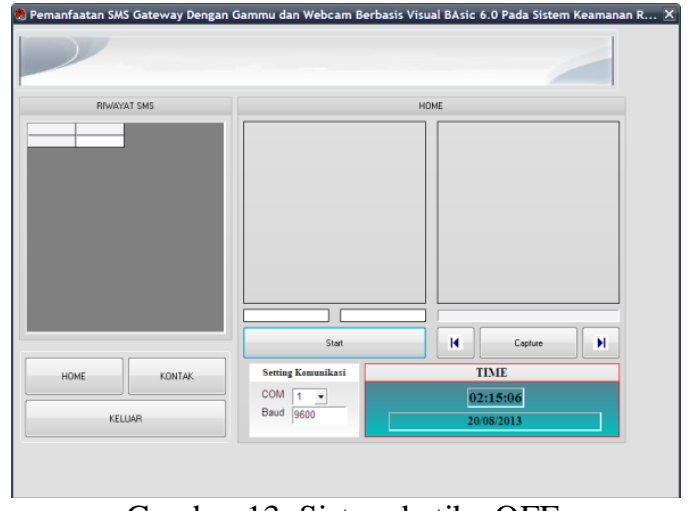

Gambar 13. Sistem ketika OFF

\section{Pengujian sistem ketika ada pergerakan}

Dalam pengujian sistem harus dalam kondisi ON yaitu kondisi sistem siap untuk menerima terigger dari mikrokontroller. Ketika menerima trigger sistem secaraotomatis akan meng-capture gambar dan mengirim sms peringatan ke nomor tujuan yang telah disimpan ke dalam database penerima. Gambar 14 adalah gambar dari sistem ketika menerima trigger dari mikrokonroller. Sedangkan gambar 15 adalah gambar handphone penerima sms.

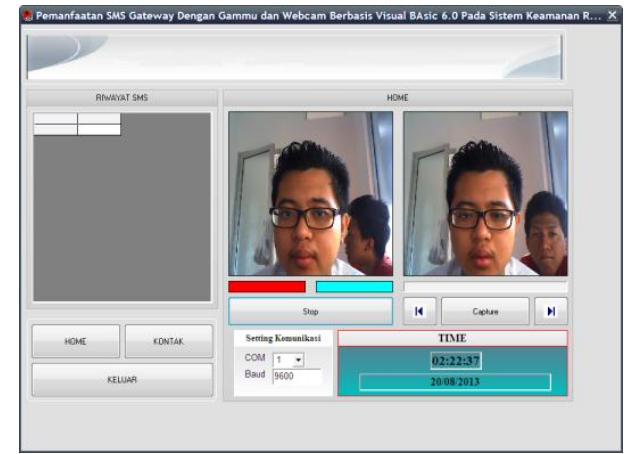

Gambar 14.Sistem ketika menerima trigger dari mikrokontroller

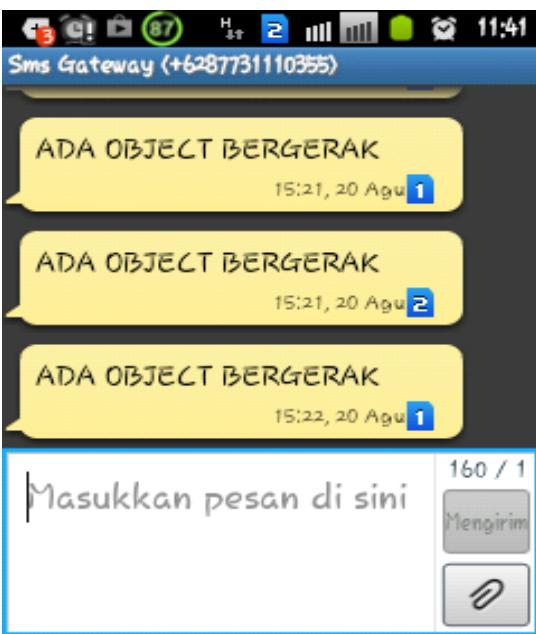

Gambar 15. Handphone Menerima SMS peringatan

\section{Pengujian sistem menambah database penerima}

Dalam pengujian sistem database penerima. Sistem harus berada pada menu Kontak. Yaitu dengan cara menekan tombol kontak untuk menambah database. Untuk menambahkan database harus memasukkan data beruoa nama dan nomor telepon setelah itu simpan database. Ketika input belum di isi maka akan muncul peringatan untuk mengisi data seperti yang terlihat pada gambar 16 .

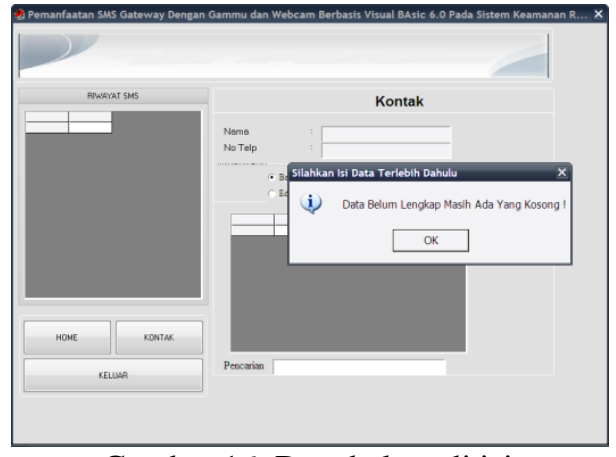

Gambar 16. Data belum di isi

Ketika memasukkan input nomor, karakter yang harus dimasukkan adalah karakter 'angka'. Apabila yang dimasukkan berupa bukan angka maka sistem akan memberi peringatan seperti yang terlihat pada gambar 17 .

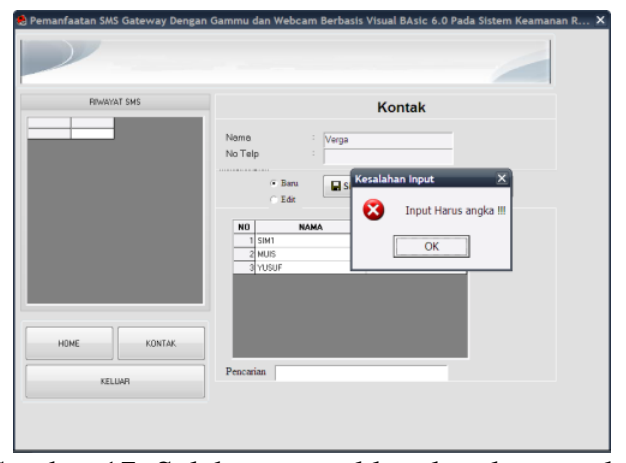

Gambar 17. Salah memasukkan karakter angka 
Ketika data tersimpan maka data akan di tampilkan pada tabel penerima seperti yang terlihat pada gambar 18.

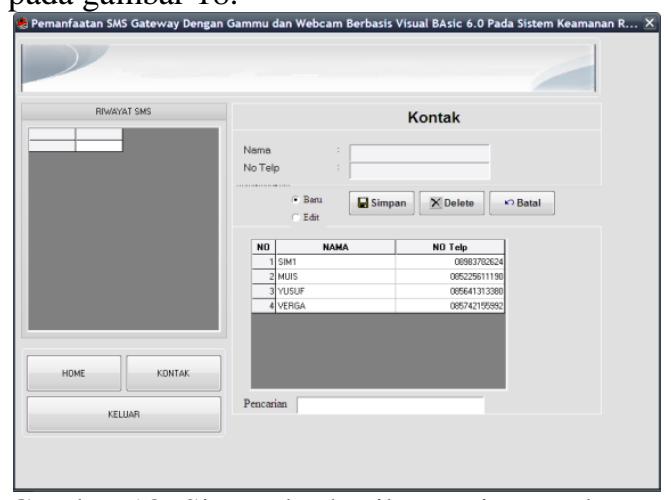

Gambar 18. Sistem berhasil menyimpan data

Gambar 19 adalah gambar tampilan database yang ada pada phpmyadmin. Pada gambar 19 terlihat bahwa data penerima sukses tersimpan pada database.

\begin{tabular}{|c|c|c|c|c|c|}
\hline \multicolumn{1}{|c|}{$\leftarrow$ T } & \multicolumn{1}{|c|}{ nama } & \multicolumn{1}{c|}{ telp } & no \\
\hline$\square$ & $\times$ & VERGA & 085742155992 & 7 \\
\hline$\square$ & $\times$ & SIM1 & 08983782624 & 4 \\
\hline$\square$ & $\times$ & YUSUF & 085641313380 & 6 \\
\hline$\square$ & $\times$ & MUIS & 085225611190 & 5 \\
\hline
\end{tabular}

Gambar 19.Tampilan database pada phpmyadmin

\section{KESIMPULAN}

Berdasarkan perancangan sistem dan hasil analisa yang didapat maka dalam pembuatan software dapat disimpulkan beberapa hal, yaitu :

- Dalam pengujian sistem aplikasi Microsoft Visual Basic 6.0 pada auto capturedan auto SMS selama 10 kali percobaan presentasi keberhasilan sistem mencapai $100 \%$.

- Dalam pengujian komunikasi port serial dengan menggunakan USB to seral RS232, setelah dilakukan percobaan selama 7 kali dan berhasil semua maka dapat disimpulkan bahwa presentase keberhasilan komunikasi serial 100 $\%$.

- Presentase pengiriman SMS $100 \%$ dengan GAMMU dan Modem Wavecom M1306B USB yang berfungsi sebagai pengirim SMS sistem, karena SMS bisa terkirim ke nomornomor yang tersimpan di database dengan ratarata waktu pengiriman adalah 17,8 detik dengan waktu terlama pada percobaan ke 3 yaitu selama 48 detik.

- Setelah dilakukan percobaan selama 6 kali yaitu dengan cara memberi trigger selama 3 kali dan capture manual selama 3 kali dan berhasil semua maka dapat disimpulkan bahwa presentase keberhasilan webcam sturdy 511 adalah $100 \%$.

- Setelah dilakukan percobaan dengan cara memasukkan 5 database penerima sms perinagatan maka dapat disimpulkan bahwa presentasi keberhasilan penyimpanan database MySQL mencapai $100 \%$.

\section{DAFTAR PUSTAKA}

1. Adie Flink, 2011, Perangkat Keras Multimedia.

2. Aplikasi PHP, 2012, File Konfigurasi GAMMU untuk Membuat Aplikasi SMS Gateway.

3. Hasballah, Fajrillah. 2009. Aplikasi Game Dan Multimedia Dengan Visual Basic. Jakarta: Elex Media Komputindo.

4. Hendarto, Chun Chun. 2009. Sistem Informasi Akademik Berbasis SMS. Bandung: Universitas Pendidikan Indonesia

5. Informatika, 2012, Mekanisme Kerja SMS, Informatika Artikel Teknik Informatika dan Sistem Informasi.

6. Prihatin, Ekawati. 2006. Aspek Keamanan Pada Jalur Komunikasi Short Message Service. Bandung: Institut Teknologi Bandung. 